\title{
SCHOOL AND PUPILS BASED FACTORS INFLUENCING GIRLS' DROPOUT RATE IN PRIMARY SCHOOLS IN WEST POKOT, KENYA
}

\author{
Nelly Andiema1i, \\ Echaune Manasi ${ }^{2}$ \\ IPhD, Department of Psychology \& \\ Early Childhood Education, \\ Kibabii University, \\ P.O. Box 1699 - 50200, Bungoma, \\ Kenya \\ ${ }^{2} \mathrm{PhD}$, Department of Educational Planning \\ and Management, \\ Kibabii University, \\ P.O. Box 1699 - 50200, Bungoma, \\ Kenya
}

\begin{abstract}
:
Girls' child education is important in any education system. However, the retention of these girls' pupils within the education system is a great challenge in Alale Zone. The study sought to establish school and pupil based factors leading to drop out among girls' pupils in primary schools in Alale Zone, West Pokot County. The specific objectives of the study were to investigate the influence school-based and pupils' personal factors on girls' dropout rate in primary schools. Maslow theory guided the study. The study was conducted in 7 primary schools in Alale Zone, North Pokot Sub County. The research design was descriptive in nature. The target population included 7 head teachers and 82 public primary school teachers. The head teachers were selected through purposive sampling while teachers were selected through simple random sampling technique. The research relied on questionnaires and interview schedules as instruments of data collection. Both validity and reliability of research instruments will be determined. The data collected was analysed using descriptive statistics and presented using frequency distribution tables, pie charts and bar and column graphs. The study established that school based and pupils-based factors influenced girls' dropout rate in the zone. Moreover, issues of teenage pregnancy, poor performance, poverty, sexual harassment and families believe and attitude contributed to increased cases of girls' dropout in schools. The study recommends that various stakeholders; government, teachers and community at large should foster efforts aimed at promoting girls' education in the zone. Guidance and counselling services need to be strengthened in primary schools in Alale Zone.
\end{abstract}

${ }^{i}$ Correspondence: email nandiema@kibu.ac.ke 
Keywords: girls' dropout rate, primary schools, Kenya

\section{Introduction}

Education is the key to the socio-economic development of nations (Nyaga, 2010). Building a quality education structure warrants a strong foundation in the form of quality primary education. Education in general and Education for All (EFA) in particular, is one of the top priorities of government of Kenya. Access to education by women is considered a significant indicator for the progress of a society. According to Andiema and Manasi (2021), the education of women in a society determines its social, financial, natural, physical and human capitals, and contributes to its growth and development. Education is a significant factor influencing the socio-economic and health conditions of the family and for determining gender relations in society. As Nobel Laureate Amartya Sen (1989) stresses, the education of women strengthens their position in the family and community and thereby produces multiple benefits. Sen argues that the education of women is the single most powerful way to encourage smaller, healthier and better educated families. As educating women helps in slowing down the population growth (Ayub, 2018) and increases productivity, encouraging the education of women and closing the gender gap in education promotes faster growth of per capita income. Owing to its considerable benefits, economists believe that investment in educating women and girls will bring the highest return for developing countries by promoting women's social and economic status (Lewin, 2007).

Students drop out, from school is a great concern for any government or society (Nyaga, 2010). Despite many policies and strategies developed to enhance a retention rate in school there are still some pupils who withdraw from school prematurely. The Universal Declaration of Human Rights, Article 26, for instance states categorically that everyone has the right to education (UN, 2013). To achieve this, the Kenya government laid down policies and allocated money in the National budget to provision of education to all children (MOE, 2007).

However, much as primary school enrolment has been a success, the concern now is with regard to the internal efficiency of primary education that is the ability to retain pupils until they graduate from primary school. The incidence of pupils dropping out of school is palpable in primary six and primary five which is 34.9 percent and 22.1 percent respectively (Ministry of Education - MOE, 2007). The problem of dropout is thus disquieting to policy makers since it partly reflects the inadequacy of a schooling system in terms of either school quality or quantity. Noteworthy to mention is that school dropouts are usually associated with chronically high unemployment levels, low earnings, and poor health outcomes (Fatuma \& Sifuna, 2006; Nyaga, 2010), and persistent poverty among certain segments of society (Chepleting, Chepkemei, Yano \& Chebet, 2013). Taken aggregately, these individual-level consequences of primary school dropouts are perilous to national development by undermining national human capital development efforts. 
In Sub-Saharan 16 Africa girls have 20\% less chance of starting school than boys. According to the UN 2013 report, in terms of girls' access to school, India is considered one of the poorest performing nations, with a gender parity index 8 of 0.81 . India is also considered a nation at risk of not achieving gender parity in both primary and secondary education by 2015 (UN, 2013) although she is legally bound, through ratification of the CEDAW and CRC, to meet the provisions for universal primary education and gender equality. Recent empirical evidence indicates a rejection of the notion of common preferences within a household, as implied in the unitary household model, instead asserting different preferences by household members (Wanyoike, 2003). In such a situation we expect difference in parental preferences to be reflected in the school participation decision of girls and boys.

In Malawi girls are found to be disadvantaged in terms of schooling and this is related to a number of factors. Firstly, fear of rape or mistreatment cause parents to delay girls' school enrolment, worrying for their girls' safety, and long distances to school aggravates this, as cited by a study by UNESCO (2014). When girls reach puberty, many parents view them as especially vulnerable, fearing pregnancy and thereby also the inability to marry them off well. A dominant course of action is therefore to withdraw the girls from school. Nevertheless, pregnancy remains one of main causes for female drop-outs (World Bank 2010; Waswa, 2015). Consequently, pregnancy acts as a doubleedged sword for girls' schooling. Secondly, a culture of early marriage leads to withdrawal of girls from school, often before finishing primary (World Bank 2010). Poverty, compounded by the incidence of shocks, has strengthened this trend as girls are married off early in order to reduce internal constraints (Krop, 2017). Thirdly, the ongoing HIV/AIDS epidemic is found to particularly affect girls' schooling, as gender-based division of labour at home implies that girls are more easily withdrawn from school to undertake household chores (UNICEF, 2007). Combining these elements results in higher drop-out rates from primary school for girls than for boys (UN 2013), especially obvious during the senior primary, and thereby reducing the entry of girls into secondary school (Waswa, 2015). In Kenya, Nyaga (2010) argues that according to completion rates in secondary schools registered $91.5 \%$ for boys and $87.5 \%$ for girls. The girls registered $12.5 \%$ drop out. In spite of the government policies to enhance enrolments in secondary sub sector, the girl's participation, retention, transition and completion at secondary school education level are lower than boys. However, Nyaga (2010) focused on secondary education but this study is aligning itself in primary education. This became a contention which the current study sought to address.

\section{Statement of the Problem}

According to Alale Area Education Office Report (2020), an average of ten dropouts is evident per year per primary school in Alale. In addition to that, every year an average of ten teachers are forced to transfer due to school dropouts especially girl child. This increasing rate of girl - child dropouts has a negative impact on the schools, communities and the country at large. For these reasons outlined, it is vital to carry out an in-depth 
study in this area to establish the main causes of girl child dropouts in primary schools. At the same time, it is also very imperative to seek possible ways of reducing or eradicating this problem in Alale Zone.

\section{Theoretical Framework}

The study was guided by Abraham Maslow theory on motivation. Gibson (1986), in an attempt to analyse the relationship between motivation and behaviour, has outlined the five basic needs of human beings in a pyramid. At the base of the pyramid are the psychological and physiological needs. Among the physiological needs are the need for food, water, sleep and rest and activity. The psychological needs include the need for affection, belonging and achievement. This theory has implications for education.

A need is a basic requirement that must be met for optimal adjustment to the environment (Gibson, 1986). This implies that if food is not available at home, girl child cannot adjust to the school environment. Therefore, hunger or starvation is a common problem to some families. The result is that the hungry children cannot cope with schoolwork and in most cases; they end up dropping out of school. Every child needs to be loved, to belong to the group and to achieve goals. Some teachers use authoritative leadership styles in the class, where children have very little to say. As a result, children feel they are not loved and lack interest in attending school. On the other hand, the use of ineffective teaching and learning methods by some teachers causes children to drop out of school, particularly the slow learners who cannot easily move along with others.

\section{Literature Review}

\subsection{School Based Factors and Girls Dropout Rate in Primary Schools}

School related issues are often viewed as minor factors for dropping out of school; however, in some cases of schooling it can be the primary determinant for a dropout (Hunt, 2008). The definition of school quality is a matter of debate and varies between studies (Sengupta \& Rooj, 2018). For instance, low quality of education and children's school attendance can be defined by under-qualified teachers (Wolf, et al., 2016), the unavailability of resources such as textbooks, desks and blackboard (Chisamya, Dejaeghere \& Kendall, 2012); teacher absence, insufficient accountability and monitoring mechanisms (Chepleting, et al., 2013), and teaching quality (Hunt, 2008). UNICEF (2007) argues that students who receive instruction in a foreign language will have a disadvantage in the educational system. This suggests that using a language different from the mother tongue affects students' ability to follow the lessons with the result of them falling behind. They argue that what might seem to be a learning problem or a matter of bad grades, resulting in repetition and dropouts, is really a language problem.

Waswa (2015) observe that when a student is admitted into school, there are certain routine procedures that take place. The student is subject to command from the teachers. Fatuma and Sifuna (2006) pointed out that in the African Society, there was the general misplaced perception that girls have to be socialized to be wives, homemakers, 
dependants and secretaries while boys are to be husbands, breadwinners, defenders and pilots. This provides a reminder of the influence of gendered thinking in education material of practice, which the study will seek to investigate. Distance to school is likely to influence school attendance and may lead to dropouts, certainly in rural areas where the distance between schools is larger (Hunt 2008; Mwihia \& Ongek, 2019). Research made by Wekesa (2014) recognized the great distance between schools in rural areas and that there are fewer secondary than primary schools; and further add that this might lead to increased dropouts in secondary school, something Wolf et al. (2016) also suggest in their study. Finally, the long distance can in some cases result in not feeling safe walking the way to school; in the cases where parents or guardians become concerned about the girls' safety, it can result in school absenteeism (Hunt, 2008).

Ayub (2018) identifies teachers' use of verbal abuse as an issue that might lead to absenteeism and dropouts. Hunt (2008) claims that bullying and physical violence emanates from both teachers and students. Also in some cases, sexual abuse is involved (Pridmore, 2007). Hunt (2007) also found that corporal punishment is frequently used in several countries, even though it is illegal, which might result in dropouts. The correlation between overcrowded classrooms and dropouts is mentioned in several studies (Wolf, et al., 2016). The problem is recognized in Zanzibar and according to Ministry of Education and Vocational Training (2007); the urge to build new classrooms is critical as most schools are overcrowded and have double or triple shifts. Krop (2017) find separate toilet facilities to be important for school quality and even more important when the girls enter puberty, for sanitary reasons. A study conducted in Ghana (Wolf et al., 2016) revealed that five out of eleven visited schools lack sanitary facilities and only one had separate toilets for boys and girls. The same study found that the unavailability of latrines in schools led to females' nonattendance during their periods, which clearly has an impact on performance and may lead to dropouts.

\subsection{Pupils Based Factors Influence on Girls Dropout Rate in Primary Schools}

The student personal attributes can lead to dropout from school. The variables include student's characteristics and pregnancy. These have different effects on various students. Once students are enrolled in school they interact and form peer groups. Wolf et al. (2016) observed that there is a simple relation between education and gender equality. Schools act as a site of pervasive gender socialization. This sometimes spurs students to think beyond the ideological limits laid on them. Wanyoike (2003) concurs with Wolf et al. (2016) and points out that the students peer groups if not guided can lead to devastating results like engage in drugs and substance abuse, early sex and then get to dangerous diseases like HIV and AIDS and early pregnancies. This leads to students dropping out of school. Thus, the study will seek to find out peer pressures that lead to student drop out of school. Permanent and temporary withdrawals from school are often a result of health issues. Even though many students go back to school, absence affects children's school achievements and reintegration negatively (Wekesa, 2014). Pridmore (2007) stresses the importance of governments' investment in public health since studies recognise the relation of health-related conditions and absenteeism among school 
children. The report The Link between Health, Social Issues, and Secondary Education: Life Skills, Health, and Civic Education (World Bank, 2010) concludes that health and civic education have an impact on children's access to secondary school. This creates a vicious circle because lower attendance in secondary school limits citizens' knowledge about public health.

Krop (2017) study recognizes a connection between females' menstruation patterns and dropouts. The report How to integrate water, sanitation and hygiene into HIV programmes (WHO, 2010) similarly illuminate the issue and estimates that $10 \%$ of African school-age girls do not attend school during menstruation or drop out when the first period occurs. The report concludes that several days of absence each month has a negative impact on girls' education and learning ability. Furthermore, those girls that have limited access to soap might not attend school because of the possibility of the period showing on the clothes; also, there is an urge for cleaner and more private toilet facilities. The problem of school pregnancies is related to rape and sexual harassment. Andiema (2021) pointed out that there are reported cases of girls 14 - 18 years, dropping out of school every year due to pregnancy and this sometimes leads to early marriages. According to Mwakio (2017), the incidence of school drop-out among females was high in rural than urban areas where pregnancy was listed as the third most common reason cited by respondents for female dropping out of school. The study sought to establish whether pregnancy was a factor leading to female students drop out of school.

In majority of African culture child bearing is associated with adults. This means pregnant girls are viewed as 'adults' and have no business being in school. Therefore, these pregnant girls are expelled from school (Chepleting et al., 2013). Fatuma and Sifuna (2006) attributes high drop out among girls due to pre-marital pregnancies which were characterized by frequent sexual harassment particularly in unaided harambee schools. There were reported cases of teachers preying on female students, threatening to fail them or publicly humiliating them to prod them in sexual relationships. Teachers are reported to reward female students who "co-operate" with grades and tuition fees waivers (Chigona \& Chetty, 2007). Such students end up being frustrated if they don't comply or if they do, they may be victims of early pregnancy and tend to withdraw from school prematurely. Wekesa (2014) observed that early withdrawal from school by girls due to pregnancy is a sexist's societal attitude manifested in gender insensitive pregnancy policies, which the study intends to highlight. The national policy of education in MOEST (2005) requires girls who are pregnant to enrol back to school. However, this is a challenge due to cultural backgrounds and the parents may be demotivated to take the girls back to school. A survey on the policy of pregnant girls required to re-enrol back to school faced a lot of challenges as reported by Wekesa (2014). It was reported that the policy lacked proper monitoring evaluation mechanisms (Fatuma and Sifuna, 2006). Worse still in some communities is where such girls are viewed as adults and are forced to early marriages. In MOE (2007) recommendations are made that a country must critically access existing policies to determine their impact on the survival of girls in schooling and then either review them or devise new ones that will help to promote gender equality and reduce female school drop-out. The study will then establish 
whether pregnancy is a factor leading girls' withdrawal from secondary schools in Alale Zone.

\section{Materials and Methods}

The study was conducted in Alale Zone, North Pokot Sub County, West Pokot County in the Republic of Kenya. The area is located on the Northern Rift Valley part of the country bordering Uganda. There are seven public primary schools in the area together with several secondary schools which most of them are public and few private. A descriptive research approach was used in this study. It is a non-experimental approach where the researcher does not undertake a practical experiment, but relies on information of what is prevailing at the time, including people's beliefs, the trends that are developing as well as the views of people (Cohen, Manion \& Morrison, 2017). Therefore, the populations who will be respondents in this project are the teachers and headteachers of 7 public primary schools in Alale Zone. This means that the population for this study was made up of 7 primary schools heads and 82 teachers. Considering the smaller number of head teachers, it will be most appropriate in this q research to include all (7) in the study while $30 \%$ of teachers will be selected from the initial (82) to act as sample. Questionnaires and interview schedules served as data collection instruments. The interview schedule was administered to head teachers while questionnaires will be prepared for teachers. In this study, analysis of quantitative data was undertaken to establish the numbers and reasons for dropouts. Descriptive statistics was used to analyse data obtained through questionnaires. Thus, data was presented in the form of tables and graphs of frequency distribution.

\section{Results and Discussion}

Children should study in an appropriate educational atmosphere and this atmosphere requires the availability of the necessary facilities like appropriate sanitation, clean and healthy potable water, desks, chairs, recreational centers, and restrooms. Inappropriate school environment negatively affects the child's educational morale and finally causes some of children to drop out of school. This is the third objective of the study that sought to determine how school-based factors: mistreatment by teachers, discrimination at school and poor performance have contributed dropout of girls in primary schools. The respondents were requested to give their responses on a Likert scale: Agree, Undecided and Disagree. The results of the analysis are as given in Table 1.

Table 1: Influence of school-based factors and girls' dropout in schools

\begin{tabular}{|l|c|c|c|c|}
\hline Influence & Agree & Undecided & Disagree & Total \\
\hline Mistreatment by teachers & $3(7.0 \%)$ & $4(9.3 \%)$ & $36(83.7 \%)$ & $43(100.0 \%)$ \\
\hline Discriminated at school & $4(9.3 \%)$ & $6(14.0 \%)$ & $33(76.7 \%)$ & $43(100.0 \%)$ \\
\hline Poor performance & $34(79.1 \%)$ & $3(7.0 \%)$ & $6(14.0 \%)$ & $43(100.0 \%)$ \\
\hline Average scores & $\mathbf{1 4}(\mathbf{3 1 . 8 \% )}$ & $\mathbf{4 ( 1 0 . 1 \% )}$ & $\mathbf{2 5 ( 5 8 . 1 \% )}$ & $\mathbf{4 3 ( 1 0 0 . 0 \% )}$ \\
\hline
\end{tabular}


As to whether mistreatment by teachers forced girls to drop out of school, $36(83.7 \%)$ disagreed, $4(9.3 \%)$ remained undecided while only $3(7 \%)$ agreed with the statement. The result implies that teachers' acts of mistreating female pupils are very rare and have minimal impact on their dropout rate in schools. Regarding the issue of discrimination at school as a contributor to girls' dropout in school, majority $33(76.7 \%)$ disagreed with the statement, $6(14 \%)$ were undecided while 4 (9.3\%) concurred with the statement. This shows that issues of discrimination rarely influence girls' dropout cases in Alale Zone. However, result of the study revealed that most $34(79.1 \%)$ of respondents agreed that poor performance in schools led to massive girls' dropout while 6 (14\%) disagreed with the statement. Average scores for the three items show that $31.8 \%$ of respondents believed that school factors influenced girls' dropout rate while $58.1 \%$ were of the opinion that school-based factors do not influence girls' dropout in primary schools in the zone.

\subsection{Pupils based factors on girls' dropout rate in primary schools}

This is the fourth objective that sought to investigate influence of pupils-based factors on girls' dropout in primary schools in Alale Zone, West Pokot County. The respondents were asked to give their opinion on how issues like pregnancy, sickness, peer pressure and immorality either contributed to dropout in schools. The results of the analysis are given in Table 2 .

Table 2: Influence of pupils-based factors on girls' dropout rate

\begin{tabular}{|l|c|c|c|c|}
\hline Influence & Agree & Undecided & Disagree & Total \\
\hline Pregnancy & $34(79.1 \%)$ & $3(7.0 \%)$ & $6(14.0 \%)$ & $43(100.0 \%)$ \\
\hline Sickness & $33(76.7 \%)$ & $6(14.0 \%)$ & $4(9.3 \%)$ & $43(100.0 \%)$ \\
\hline Peer pressure & $31(72.1 \%)$ & $6(14.0 \%)$ & $6(14.0 \%)$ & $43(100.0 \%)$ \\
\hline Immorality & $30(69.8 \%)$ & $5(11.6 \%)$ & $8(18.6 \%)$ & $43(100.0 \%)$ \\
\hline Average scores & $32(74.4 \%)$ & $5(11.6 \%)$ & $6(14.0 \%)$ & $\mathbf{4 3 ( 1 0 0 . 0 \% )}$ \\
\hline
\end{tabular}

Result show that 34 (79.1\%) of teachers agreed that early pregnancy cases among girls in schools forces them to drop out of school. The results paint a grim picture on the increased cases of pregnancy among girls in primary schools in the zone which destabilises their personal and academic life. It was also evident from 33 (76.7\%) of respondents who reported that sometimes girls are forced to drop out of schools due to sickness. Results further show that 31 (72.1\%) of teachers agreed that peer pressure usually force some girls to drop out of school while $30(69.8 \%)$ of respondents were found to accept that immorality cases among girls made them to miss schools in Alale Zone. Average score shows that $32(74.4 \%)$ of teachers agreeing with the statement that pupils personal based factors significantly influence dropout rate in schools with only 6 (14\%) disagreeing with the statement.

\section{Conclusions and Recommendations}

The main school factor identified to cause massive dropout cases was poor performance. Most girls were discouraged by their teachers, parents and fellow pupils that they cannot 
make it in academics and this was cited to be a contributor to the increased dropout cases. Findings showed that the respondents strongly agreed (74.4\%) that pupils' personal characteristics and behaviours contributed to dropout in schools. For example, cases of early pregnancy, immorality, peer pressure and general sickness were found to influence girl child dropout rate in Alale Zone, West Pokot County. The study notes that if girls are not educated, the society will lose the economic and social benefits associated with the female literacy and schooling. The study recommends that teachers should also work to create inclusive learning friendly environments and to encourage and guide learners on how to go about the difficulties they experience. Action should be taken on culprits who impregnate girls and put them in difficult situations. The victims' girls should be rehabilitated and given a chance to get back to school.

\section{Conflict of Interest Statement}

The authors declare no conflicts of interests.

\section{About the Authors}

The author (Dr. Nelly Andiema) and co-author (Dr. Echaune Manasi) are lecturers at Kibabii University School of Education. Dr. Andiema specialty is in Early Childhood Education, Primary Education, Special Needs and Gender Related Studies. Dr. Echaune Manasi specialises in teaching Educational Planning and Management, Research and Consultancy courses.

\section{References}

Andiema, N., \& Manasi, E. (2021). Female students' participation in technical vocational education and training in West Pokot County, Kenya. East Africa Journal of Education Studies, 3(1), 61 - 69. https://doi.org/10.37284/eajes.31.314

Andiema, N.C. (2021). Influence of culture on girl child education in Central Pokot Sub county, Kenya. East African Journal of Education Studies, 3(1), 26 - 38. https://doi.org/10.37284/eajes.3.1.279

Ayub, M.J. (2018). Factors contributing to low completion rates of girls in primary schools in Mogotio Sub County, Baringo County, Kenya. International Journal of Scientific Research and Innovation Technology, 2(6), $20-35$.

Chepleting, S., Chepkemei, A., Yano, K.L. \& Chebet, L.L. (2013). Factors influencing girls participation in free primary education: A survey of schools in Kapenguria Division, West Pokot County, Kenya. International Journal of Business and Commerce, 2(6), $20-35$.

Chigona, A. \& Chetty, R. (2007). Girls education in south Africa: Special consideration to teen mothers as learners. Journal of Education for International Development, 3(1), 1 17. 
Chisamya, G. \& Dejaeghere, J. \& Kendall, M. (2012). Gender and education for all: Progress and problems in achieving gender equity. International Journal of Education Development, 32(6), 743 - 755.

Cohen, L., Manion, L. \& Morrison, K. (2017). Research methods in education. London: Routledge.

Fatuma, N.C. \& Sifuna, D.N. (2006). Girls and Women's Education in Kenya: Gender perspectives and trends. Nairobi: UNESCO.

Gibson, J.T. (1986). Education psychology. London: Permagon Press.

Hunt, F. (2008). Dropping out from school: A cross-country review of literature, CREATE Pathways to Access No 16. Consortium for Research on Educational Access, Transitions and Equity: University of Sussex.

Krop, A.L. (2017). Influence of institutional factors on girls completion rates in primary education in Central Pokot Sub County, Kenya. M.Ed Project, University of Nairobi.

Lewin, K.M. (2007). Improving Access, Equity and Transitions in Education: Creating a Research Agenda. CREATE Pathways to Access Series, No 1. Brighton: University of Sussex.

MOE (2007). Gender Policy in Education. Nairobi: Government Printer.

Mwakio, N. (2017). Overcoming obstacles to educational access for Kenyan girls: A qualitative study. Journal of International Women's Studies, 18(2), 260 - 274.

Mwihia, C. \& Ongek, M. (2019). Factors influencing boy child dropout from public secondary schools in Kinangop Sub County, Nyandarua County, Kenya. European Journal of Education Studies, 6(7), 541 - 564.

Nyaga, A.M. (2010). Factors Leading to Drop Out Among Female Students in Secondary Schools in Runyenjes Division of Embu East District, Kenya. Thesis, Chuka University, Kenya.

Pridmore, P. (2007). Impact of Health on Education Access and Achievement: A Cross-National Review of the Research Evidence. UK: University of Sussex.

Sen, A. (1999) Development as Freedom. New York: Alfred A. Knopf.

Sengupta, R., \& Rooj, D. (2018). Factors affecting gender disparity in Muslim education in India. Journal of Development Policy and Practice. https://doi.org/10.1177/2455133317737936

UN (2013). UIS Data Centre: Primary Education (ISCED 1) Drop Out Rate. Retrieved online from https://www.data.uis.unesco.org (Accessed on Dec 2021).

UNESCO (2014). The state of the world's children. Girls education and development, $434-$ 435.

UNICEF (2007). A human rights based approach to education for all. New York: UNICEF.

Wanyoike, W. (2003). Understanding Youth and Family from a Christian Perspective. Nyeri, Kenya: Wilson Wanyoike publisher.

Waswa, A.W. (2015). Factors affecting girl-child progression rates in primary schools in ASAL areas: A survey of West Pokot Sub County in West Pokot County Kenya. M.Phil Thesis, Moi University. 
Wekesa, V. (2014). Re-admission policy and Kenya Certificate of Secondary Education Performance in Bungoma North Sub County, Kenya. International Journal of Innovative Research \& Development, 3(7), 436 - 441.

Wolf, S., McCoy, D.C., \& Godfrey, E.B. (2016). Barriers to school attendance and gender inequality: Empirical evidence from a sample of Ghanaian school children. Research in Comparative and International Education, 11(2), 178 - 193. Doi: $10.1177 / 1745499916632424$ to copy, distribute, transmit or adapt the article content, providing a proper, prominent and unambiguous attribution to the authors in a manner that makes clear that the materials are being reused under permission of a Creative Commons License. Views, opinions and conclusions expressed in this research article are views, opinions and conclusions of the author(s). Open Access Publishing Group and European Journal of Education Studies shall not be responsible or answerable for any loss, damage or liability caused in relation to/arising out of conflicts of interest, copyright violations and inappropriate or inaccurate use of any kind content related or integrated into the research work. All the published works are meeting the Open Access Publishing requirements and can be freely accessed, shared, modified, distributed and used in educational, commercial and non-commercial purposes under a Creative Commons Attribution 4.0 International License (CC BY 4.0). 